
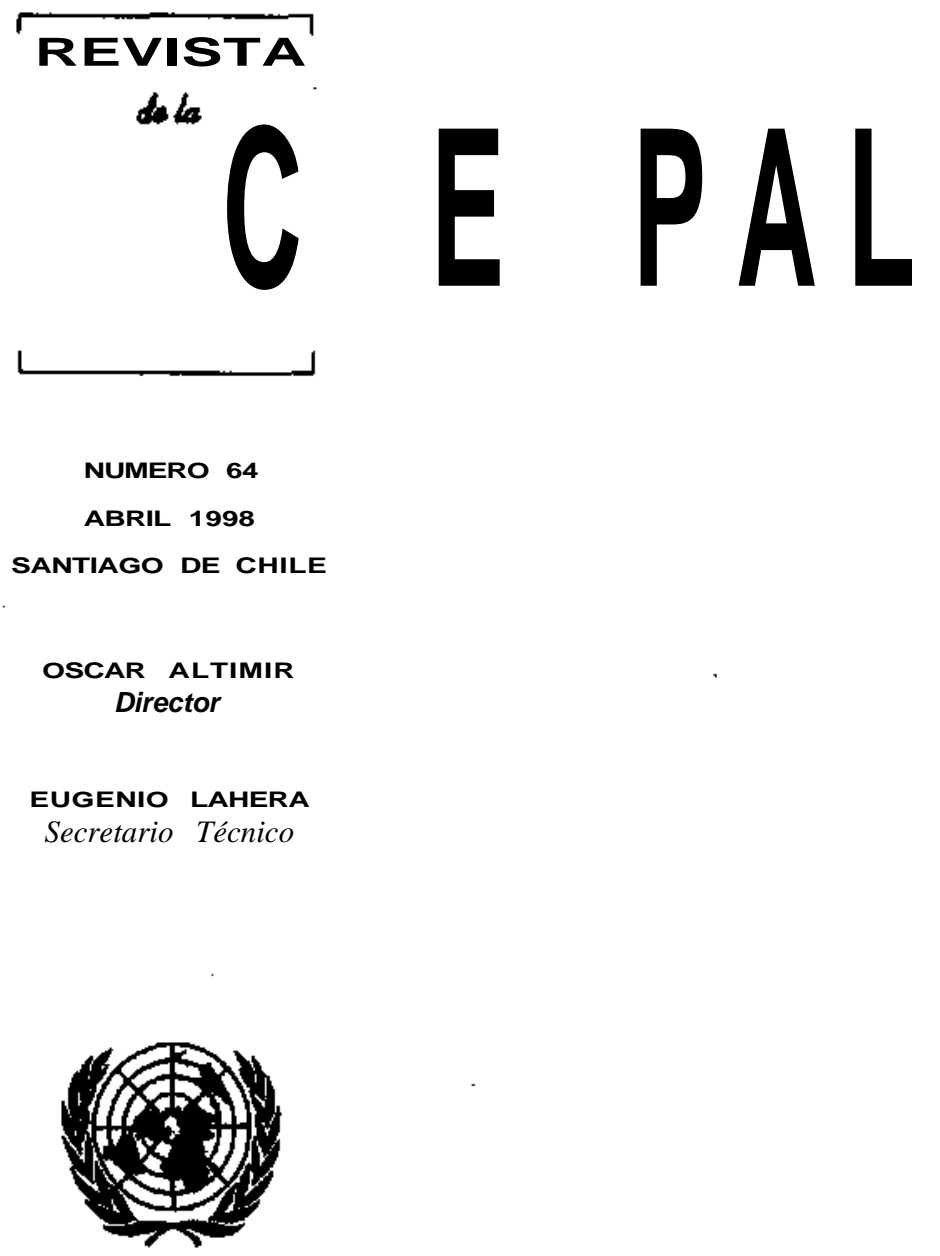

NACIONES UNIDAS 
Instituciones y crecimiento ¿Puede el capital humano ser un vínculo?

Nauro Campos y Jeffrey B. Nugent

Flujos de capital externo en América Latina y el Caribe en los años noventa: experiencias y políticas

Gunther Held y Raquel Szalachman

El Banco Central y la política macroeconómica de Chile en ios años noventa

Roberto Zahler

Política fiscal, ciclo y crecimiento

Ricardo Mariner

La convergencia hacia mejores prácticas productivas y de políticas: el acuerdo de la OMC sobre medidas de inversión vinculadas al comercio

Francisco Sercovich

Efectos para América Latina de la expansión de la Unión Europea

Peter Nunnenkamp

La dimensión Norte-Sur de las industrias de limpieza ambiental

y la difusión de tecnologías limpias

Jonathan R. Barton

La evolución del papel del Estado en la regulación del transporte terrestre

lan Thomson

Manejo integrado del recurso agua, con la perspectiva de los

Principios de Dublin

Miguel Solanes

Publicaciones recientes de la CEPAL 


\section{Manejo integrado del recurso agua, con la perspectiva de los Principios de Dublin}

\section{Miguel Solanes}

Asesor Regional en

Legislación de

Recursos Hídricos y

Regulación de

Servicios Públicos, CEPAL.
En el presente artículo se analiza la relación entre los Principios de Dublin de 1992, la planificación integrada del agua y la legislación respectiva. En los Principios de Dublin se intentó resumir asĩ los principales aspectos y propósitos de la gestión del agua: el agua dulce es un recurso finito y vulnerable, esencial para sostener la vida, el desarrollo y el medio ambiente; el aprovechamiento y la gestión del agua deben inspirarse en un planteamiento basado en la participación de los usuarios, los planificadores y los responsables de las decisiones a todos los niveles; la mujer desempeña un papel fundamental en el suministro, la gestión y la protección del agua; y el agua tiene un valor económico en todos los diversos usos a los que se destina y debería reconocérsele como un bien económico. No se pretende en este artículo refrendar ningún modelo o solución determinados, sino describir una serie de opciones y experiencias que puedan ser útiles para los lectores que deseen informarse sobre los aspectos institucionales de la gestión del agua. El derecho de aguas ofrece en todo el mundo ejemplos de planteamientos sistémicos de la gestión de los recursos hídricos que incluyen, en forma más o menos completa, los principios y las normas de la gestión y planificación integradas del agua. Sin embargo, son diferentes el tipo de enfoque y sus grados de desarrollo. Entre las diferencias cabe destacar las que se refieren a la ética de la gestión integrada del agua, la capacidad de los organismos encargados, la participación, generalmente escasa, del público, la información, los derechos de agua y la planificación, la fijación del precio del agua y los límites de la planificación. 


\section{I}

\section{Introducción ${ }^{1}$}

En este documento las políticas, la planificación y la gestión integrada se consideran pasos de un solo proceso unitario, no siempre armónico. Se trata en este artículo de identificar las materias, los temas y los elementos de juicio que interesan a la planificación y sugerir aspectos en que tendría que desarrollarse más la legislación para mejorar la toma de decisiones. Se supone que el objetivo final de un proceso de planificación es la consideración óptima y la mejor integración posible de los elementos ambientales, económicos y sociales en una gestión sustentable de los recursos hídricos.

El agua no es un bien ordinario. Es un elemento natural, fundamental para los procesos ambientales, el bienestar social, la actividad económica y el desarrollo. Reúne características económicas especiales que abarcan, entre otros, aspectos de bien público; externalidades; competencia imperfecta; riesgo, incertidumbre e información imperfecta; potencial para ineficiencias sociales y ambientales y falta de equidad, y vulnerabilidad a creación de monopolios. ${ }^{2}$ Por ello, la Sociedad Estadounidense de Ingenieros Civiles respalda la legislación que reconoce que el agua, por su misma naturaleza, debe someterse a la gestión integrada y recibir los beneficios de una planificación global (Matthews, 1994).

En términos operacionales, la gestión integrada del agua puede entenderse al menos de tres formas: la integración de los diferentes componentes del agua; la integración de los intereses y recursos hídricos, terrestres y ambientales; y la integración de! agua en el de-

\footnotetext{
${ }^{1}$ Los Principios de Dublin fueron aprobados en la Conferencia Internacional sobre el Agua y el Medio Ambiente, celebrada en Dublin, del 26 al 31 de enero de 1992. Constan de cuatro postulados principales establecidos en la Conferencia, que se comentan en el presente artículo, con el objeto de relacionarlos con la gestión integrada de los recursos hídricos y el derecho de agua. Dichos principios son: $1^{\mathrm{o}}$ el agua dulce es un recurso finito y vulnerable, esencial para sostener la vida, el desarrollo y el medio ambiente; $2 "$ el aprovechamiento y la gestión del agua deben inspirarse en un planteamiento basado en la participación de los usuarios, los planificadores y los responsables de las decisiones a todos los niveles; $3^{\circ}$ la mujer desempeña un papel fundamental en el suministro, la gestión y la salvaguardia del agua, y $4^{\circ}$ el agua tiene un valor económico en todos sus diversos usos en competencia a los que se destina y debería reconocérsele como un bien económico.

${ }^{2}$ Véase, en general, Colby-Saliba y Bush, 1987.
}

sarrollo social y económico (Mitchel (ed.), 1989, p. 203).

El concepto de planificación puede entenderse de dos maneras: como un sistema de planes, o como una metodología para lograr ciertos fines. Aunque el presente artículo se refiere principalmente a conceptos técnicos y metas definitivas como sustentabilidad, eficiencia y equidad, procura también plantear algunos conceptos de gestión estratégica calcados del sector privado. El trasplante de conceptos obedece a la necesidad de obviar la rigidez, el determinismo y la falta de evaluación racional que se han advertido en los proyectos de algunos sistemas nacionales de gestión del agua. Por lo demás, hay ejercicios de gestión del agua en países en desarrollo - sobre todo los que se ocupan del agua como insumo o bien intermedio- que parecen suponer que los productos vinculados con el agua no entran en la competencia general de los mercados. En cambio, la gestión privada empresarial del agua ha tomado plena conciencia de la dinámica de mercados en todas sus ramas.

En algunos países en desarrollo la gestión del agua abarca políticas públicas destinadas a múltiples objetivos vinculados con el desarrollo, la descentralización y la protección del medio ambiente, sin que se dé tiempo ni recursos suficientes para recopilar datos, medir capacidades y definir estrategias prácticas. Aunque son legítimos los objetivos de fondo de esas políticas, su puesta en práctica se beneficiaría de la experiencia del sector privado que escalona sus actividades, según prioridades y capacidades sustantivas, dentro de una estrategia global.

Algunas experiencias y decisiones recientes en América Latina, como la construcción de presas en el oeste de la Argentina, plantean cuestiones éticas relacionada con la política y la planificación del agua, tema que no siempre se considera en la planificación de los recursos hídricos, pero que parece formar parte infaltable de la gestión estratégica privada moderna.

Con relación a los recursos hídricos, las nociones de ética están muy emparentadas con las de eficiencia y equidad. La eficiencia en el uso de recursos hídricos escasos es un requisito de la sustentabilidad. Sin embargo, pocos sistemas jurídicos contienen normas de 
aplicación forzosa en lo que se refiere a los estándares y los umbrales para la evaluación económica y social de proyectos, y casi ninguno contiene recursos legales que permitan al público cuestionar efectivamente los programas, alegando ineficiencia económica o falta de equidad social.

En muchos aspectos la equidad está estrechamente relacionada con la eficiencia, puesto que la carga de las decisiones públicas ineficientes, habitualmente encarnadas en subsidios que agobian al contribuyente, pesa sobre la población al elevarse los impuestos y mermar fondos para los servicios públicos. Otra dimensión de la equidad es la posibilidad de acceder a los recursos hídricos y sus productos a precios razonables. Los sistemas que facilitan el monopolio no favorecen la equidad. El acceso y la competencia se bloquean y los precios son más elevados de lo que habrían sido en un sistema competitivo.

En la jurisprudencia las normas destinadas a proteger los valores ambientales - tanto en materia sustantiva como de procedimiento- parecen haber evolucionado más que las que disponen la protección contra la toma de decisiones económicamente ineficientes, pese al hecho de que el análisis económico cuenta con métodos bien establecidos de evaluación.

Es así como grupos bien situados pueden ocasionalmente obtener beneficios concretos, gracias a subsidios derivados de evaluaciones económicas inadecuadas. Un fenómeno paralelo es la captación, por el sector privado, de los reguladores de los servicios de utilidad pública — tema bien conocido-y de los responsables de las decisiones sobre proyectos de gestión y aprovechamiento de los recursos hídricos.

También interesa el tema del liderazgo. En algunos sistemas hay buenos técnicos que preparan propuestas sensatas que luego son descartadas sistemáticamente en los niveles de política sensibles a los intereses creados.

El presente artículo, que toca los temas de legislación, planificación, organización, participación, financiamiento y capacidad, se ha organizado conforme a los encabezamientos de los principios de Dublin.

II

\section{El agua dulce es un recurso finito y vulnerable, esencial para sostener la vida, el desarrollo y el medio ambiente}

\section{Políticas}

Antes que nada importa determinar cuáles son los fines generales de la gestión de los recursos hídricos. Howe y Da Cunha afirman que el principio rector es el logro de la equidad y la eficiencia, a lo que parece apropiado agregar "dentro de un contexto de desarrollo sustentable" (Howe, 1996a p. 30; Da Cunha, 1989, pp. 57 a 69 y Howe, 1996b).

Varios países establecen los propósitos y objetivos de sus políticas de recursos hídricos en su legislación de aguas. La definición de políticas atañe a la interpretación, aplicación y cumplimiento de la legislación sobre la gestión integrada del agua.

La nueva ley brasileña sobre políticas de recursos hídricos y sistema nacional de gestión del agua es un buen ejemplo de esta tendencia: el agua es un bien público con valor económico y es susceptible de múltiples usos; debe manejarse a nivel de cuencas según los principios de la descentralización y participación (ley de aguas $\mathrm{N}^{\circ} 9433$ de 8 de enero de 1997). La ley persigue múltiples objetivos: la protección de los intereses de las generaciones futuras, la utilización integrada y racional, el desarrollo sustentable, la prevención de los desastres naturales y la protección contra sus efectos (art. 2). La ley establece principios jurídicos para la ejecución de la política nacional de recursos hídricos. Ellos son: un enfoque sistémico que integra criterios de calidad y cantidad de agua; el ajuste de los principios de gestión a situaciones regionales concretas; la integración entre la gestión del agua y objetivos ambientales; la integración de usuarios, regiones, estados y el gobierno nacional en el proceso de planificación; la integración entre la gestión del agua y del suelo; y la integración de cuencas, estuarios y zonas costeras.

Varias leyes contienen principios de política que reconocen las funciones múltiples del agua. 
La ley de aguas de Canadá de 1970 fomenta el uso óptimo de los recursos hídricos para beneficio de todos los canadienses (art. 1). La ley de evaluación ambiental de 1992 dispone que los efectos ambientales de los proyectos se consideren detenidamente y que se promueva el desarrollo sustentable para lograr un medio ambiente y una economía sanos; vela porque los proyectos no causen daños ambientales significativos y que haya participación del público. La ley se aplica a proyectos en que el gobierno federal tiene autoridad decisoria.

La ley de aguas de China de 1988 se propone asegurar el desarrollo, la utilización y la protección racional de los recursos hídricos, aprovechando plenamente los beneficios del agua para el desarrollo económico y el sustento de la población.

La ley de aguas de Alemania (en su versión enmendada del 23 de septiembre de 1986) dispone que el agua (tanto superficial como subterránea) se administre de manera tal que sirva al interés común, con beneficio para el usuario individual y sin un impacto perjudicial evitable (art. I a).

La ley de gestión de recursos naturales de 1991 (que incluye el agua) de Nueva Zelandia define el significado jurídico de la sustentabilidad: satisfacer las necesidades razonablemente previsibles de las generaciones futuras; proteger la capacidad sustentadora de vida del agua, el suelo, el aire y los ecosistemas y evitar, mitigar y corregir daños sobre el medio ambiente. Proporciona los elementos de juicio y las normas para medir la sustentabilidad. Estos se dividen en dos grupos jerárquicos, "asuntos de importancia nacional" y "otros asuntos", que deben considerarse en la toma de decisiones. Comprenden aspectos ambientales, sociales y económicos.

La política sobre gestión del agua de los Países Bajos de 1991 establece la gestión integrada de los recursos hídricos, incluidos los aspectos cuantitativos y cualitativos.

Algunos sistemas como el de Mississippi, en los Estados Unidos, incluyen detalles de metas, objetivos, medios e instrumentos: máximo aprovechamiento útil, ausencia de derroche, máximo desarrollo económico compatible con otros usos; protección ambiental; avenamiento y control de crecidas; almacenamiento del agua; autorización de permisos; preservación y mejoramiento de la calidad del agua; políticas de recursos hídricos; situaciones de emergencia.

Las conexiones entre las condiciones (y planes o programas) socioeconómicas generales y el uso y protección de los sistemas naturales han sido señaladas específicamente en el informe Bruntland. Japón, Polonia y Nigeria, así como Francia, se proponen integrar la gestión del agua en sus políticas y planes socioeconómicos nacionales (Mitchel (ed.), 1989, pp. 203 a 204).

El concepto de la gestión integrada del agua no es sólo una cuestión de interés nacional. En Europa, el Acta Única Europea (CEE) de 1986 adoptó el principio de una política ambiental comunitaria, que hace posible considerar la ejecución de políticas de gestión integrada de los recursos hídricos, prestando especial atención a las medidas no estructurales de la gestión del agua (Da Cunha, 1989, pp. 57 a 69).

\section{Integración de elementos ambientales en el de- recho de aguas}

La dimensión ambiental del agua es un componente principal de la legislación respectiva. Permisos, prohibiciones y tarifas se utilizan para evitar el deterioro del agua, así como de otros recursos naturales y activos ambientales conexos.

La ley de aguas canadiense establece zonas de gestión de la calidad del agua y dispone la ejecución de esos programas (art. 11). Los organismos encargados planificarán, iniciarán y llevarán adelante programas para recuperar, preservar y mejorar la calidad de las aguas dentro de la zona de gestión (art. 13).

La ley de aguas de China estipula que es deber del Estado proteger y mejorar el medio ambiente. La agricultura debe practicarse con miras a promover un rendimiento agrícola estable y elevado (art. 15). El aprovechamiento hidroeléctrico debe hacerse de acuerdo con la protección del medio ambiente (art. 16). Deben impedirse los impactos ambientales adversos en las obras de transferencia entre cuencas (art. 21). Hay otras normas que controlan la eliminación de desechos, las actividades mineras, la recuperación de suelos, la construcción de obras y la creación de zonas de gestión y protección (arts. 24 a 29).

La ley de aguas de Alemania establece el deber general de impedir la contaminación del agua y aquellos cambios que deterioren su calidad; asimismo exige un uso económico del agua en resguardo de los recursos hídricos naturales (art. la). Las aguas pueden estar sujetas a parámetros de caracterización impuestos por el gobierno federal (art. 36b). La ley dispone asimismo condiciones adecuadas de caudal, mantenimiento de la navegación, exigencias ecológicas, características panorámicas, protección de las riberas y autopurificación (art. 27). 
La política ambiental y de recursos hídricos de los Países Bajos se propone como objetivo principal tener y mantener un país seguro y habitable y desarrollar y mantener sistemas hídricos saludables que garanticen su utilización sostenida (Mitchel (ed.), 1989, pp. 203 a 204). Los criterios de ejecución para esa política incluyen el uso racional o "guiado" de los recursos hídricos, en particular del agua subterránea. Se exige la preparación de planes de acción cada cinco años para combatir la contaminación del agua (Mitchel (ed.), 1989, pp. 8 y 9).

En algunos sistemas los intereses ambientales constituyen la base para enmendar, restringir, prorratear o anular derechos de agua existentes. La ley de aguas de Francia de 1992 autoriza la modificación de los derechos de agua cuando la salud pública o la seguridad así lo exigen, o cuando los medios acuáticos estén amenazados (art. 10.iv). En los Estados Unidos la doctrina de la tutela pública se utilizó para limitar los derechos de asignación previa cuando el pleno ejercicio de tales derechos habría significado secar un lago. ${ }^{1}$

\section{Integración del agua superficial y subterránea y los recursos de tierra}

La protección de las fuentes de agua mediante el control del uso y la habilitación de la tierra, ha sido una preocupación tradicional del derecho de aguas. El crecimiento de la demanda y de las externalidades ha acentuado esta inquietud.

La regulación del uso de la tierra y del agua se remonta al derecho romano. La actio aquae fiuviae arcendae fue un medio judicial para proteger a los propietarios aguas abajo de las modificaciones artificiales introducidas en el escurrimiento de las aguas lluvias. La regulación moderna de la tierra se basa en el poder de policía del Estado y pretende proteger a la población. Incluye la regulación de la expansión y de los loteos urbanos y del uso de las llanuras aluviales y del campo abierto. Esta última regulación tiene por objeto evitar perjuicios y proteger contra las inundaciones tanto las zonas circundantes como la flora y la fauna.

Entre las regulaciones en materia de tierras figuran la restricción a la instalación de vertederos para proteger las corrientes de agua e impedir la contami-

\footnotetext{
${ }^{3}$ Mono Lake, National Audubon Society v. Superior Court of Alpine County, 33 Cal.3d 419, 189 Cal.Rptr. 346, 658 P.2d 709(1983).
}

nación del recurso, la preservación de [os humedales y el control de las zonas costeras y del dragado. Otras actividades que implican control son la minería, la explotación de canteras, la agricultura, la silvicultura, el aprovechamiento del litoral y de las playas, las zonas protegidas y el control del uso de la tierra para proteger el abastecimiento de agua (Wright y otros, 1978, pp. 172 a 175).

La ley de aguas de Alemania dispone la creación de zonas de protección de aguas, en las cuales no pueden desarrollarse ciertas actividades o en que hay que tolerar ciertas restricciones (art. 19). La ley de gestión de recursos de Nueva Zelandia de 1991 y la ley de aguas de Brasil de 1997 exigen la consideración conjunta de la gestión del agua, la tierra y el suelo.

En el Reino Unido la ley de aguas de 1989 y la ley de recursos hídricos de 1991 disponen la protección contra la sedimentación, la creación de zonas de protección hídrica y de las zonas sensibles al nitrato, las buenas prácticas agrícolas y la gestión empresarial de la tierra y el agua. La autoridad fluvial nacional tiene el mandato general de llevar adelante una gestión adecuada que incluya conservar, redistribuir, aumentar y asegurar el uso adecuado del abastecimiento de agua en Inglaterra y Gales. Para tal fin pueden establecerse sistemas de gestión de los recursos hídricos.

Hoy por hoy se reconoce que el agua subterránea debe controlarse y protegerse. Varios países han promulgado leyes que protegen las zonas de recarga, crean zonas de gestión especiales y promueven el uso conjunto del agua superficial y subterránea. ${ }^{4}$

\section{La planificación del agua}

En sus comienzos, la gestión integrada respondía a inquietudes concretas que vinculaban el agua con otros recursos ambientales. Por lo tanto, los primeros pasos de la integración relacionaban la gestión del agua con la degradación de la tierra y la erosión del suelo, para evolucionar luego hacia objetivos más amplios, como el control de crecidas, la energía hidroeléctrica y el transporte en cuencas fluviales (Mitchel (ed.), 1989, p. 203).

Las facultades legales del gobierno para planificar y regular el uso del agua y demás recursos emanan de diversas fuentes:

\footnotetext{
${ }^{4}$ Se puede hallar información más detallada sobre las prácticas vigentes en la gestión del agua subterránea en Beck y Gloperud,
} (eds.), 1991. 
i) la propiedad del recurso, porque el agua es generalmente de propiedad pública;

ii) la tutela pública;

iii) la autoridad financiera cuando se trata de proyectos financiados con fondos fiscales;

iv) la promoción del bienestar, que es atribución del gobierno estatuida en algunas constituciones nacionales;

v) la regulación del comercio y la navegación;

vi) el poder fiscalízador derivado de la condición soberana de los Estados, que les da derecho a una regulación razonable de los bienes y la conducta del sector privado;

vii) y la prevención, alivio y reparación de perjuicios. Los derechos de agua son de propiedad privada y como tales están sujetos a regulación. Esa regulación, derivada del poder fiscalizados no debe ser arbitraria, caprichosa, irracional, irrazonablemente discriminatoria o equivalente a la confiscación de la propiedad privada. Este es un tema jurídico muy discutido. Se ha estimado aceptable la regulación siempre y cuando la propiedad reporte una rentabilidad prudente y el propietario mantenga una variedad razonable de usos posibles. Se acepta también la regulación para impedir daños.

Los países suelen combinar la legislación, el compromiso político y las decisiones administrativas para fomentar la gestión integrada del agua.

La ley de aguas de China exige que el desarrollo y la utilización del agua y la prevención de desastres se planifiquen de manera cabal y sistemática, teniendo en cuenta todos los aspectos, para un aprovechamiento múltiple que rinda los máximos beneficios, lomando en cuenta plenamente todas las funciones del' agua (art. 4). Hay planes integrales para las cuencas de los ríos principales y planes sectoriales especiales. Los planes integrales - preparados por los departamentos de recursos hídricos de los diferentes niveles de gobierno- se coordinan con el plan nacional de tierras, considerando las demandas de diferentes regiones y sectores. Los planes sectoriales especiales se elaboran en los departamentos interesados (art. 11) y se aplican medidas correctivas o, en su defecto, indemnizaciones en caso de interferencia con los proyectos existentes (art. 20).

El sistema francés se centra en torno a dos elementos esenciales: las cuencas hidrográficas (todas las aguas que afluyen a un mismo río, lago o mar) y las unidades hidrográficas (determinados ríos o acuíferos).

Las cuencas o grupos de cuencas hidrográficas están cubiertas por los planes maestros de aprovecha- miento y gestión del agua. Determinan los objetivos generales de la calidad y cantidad del agua y las obras que deben realizarse para tal fin. Los prefectos regionales inician el proceso, que es llevado a cabo por los comités de cuencas. Participan en el proceso los interesados en el agua de la cuenca. Los planes - que son quinquenales - tienen que ser aprobados por las autoridades administrativas para luego ser dados a conocer a la opinión pública.

Los ríos y los sistemas de acuíferos o grupos de subcuencas están regulados por los planes de aprovechamiento y gestión de los recursos hídricos, a los que prestan coherencia los planes maestros. Estos definen los objetivos generales del uso y aprovechamiento y la protección cualitativa y cuantitativa del agua superficial y subterránea, los humedales y los ecosistemas acuáticos. Los planes de gestión son preparados, revisados y supervisados por comisiones especiales, compuestas de representantes de las comunidades locales, usuarios, propietarios, habitantes ribereños, organizaciones profesionales, el gobierno central y sus órganos públicos. La participación es, por lo tanto, una meta específica del sistema. Antes y después de su aprobación administrativa, los planes de gestión son dados a conocer a la opinión pública para que formule sus comentarios y observaciones. Pueden establecerse comunidades locales de aguas con facultad de poseer las obras, instalaciones y estructuras desarrolladas en virtud del plan.

La ley de aguas de Alemania exige la aprobación previa del plan antes de autorizar cualquier modificación substancial de las masas de agua y sus riberas (art. 31), Las cuencas fluviales y las regiones económicas estarán sujetas a dichos planes, a fin de resguardar los recursos hídricos necesarios para el mejoramiento económico y la protección de la calidad de vida. Los planes deben considerar los recursos hídricos disponibles, el control de las crecidas y la protección contra la contaminación, integrando la planificación del agua en la planificación regional. Los planes están sujetos a ajustes y actualizaciones. Son ejecutados con una variedad de instrumentos, que incluyen, entre otros, exigencias administrativas y revocación de permisos y licencias (art. 36b).

En Nueva Zelandia, cuando las autoridades locales estudian el establecimiento de objetivos, políticas y normas en virtud de la Parte V de la ley de gestión de recursos naturales, están obligadas a considerar la congruencia de la decisión que adopten y de los medios para concretarla con los objetivos de la ley; los demás medios para alcanzar los fines que persigue la 
decisión; las razones a favor y en contra de la decisión, que incluyen la decisión de no innovar; la evaluación de costos y beneficios; y el convencimiento de que la decisión es el medio más eficaz de ejercer sus funciones.

El enfoque se basa en objetivos de desempeño y no es prescriptivo. Por eso, el uso de los lechos de ríos y lagos y de los recursos hídricos, incluso la sustracción o el vertimiento, debe permitirse conforme a las normas de los planes o autorizaciones regionales (ley de gestión de recursos, sec. 13/14).

Los planes regionales deben incluir, entre otros, los conflictos entre el uso o aprovechamiento y la conservación, y el modo de evitar o mitigar esos conflictos; las necesidades y demandas de protección especial; los peligros naturales o artificiales que puedan evitarse o mitigarse; la demanda de recursos naturales; los intereses de los aborígenes; formas de restaurar, evitar y mitigar el daño; los usos de la tierra y del agua que afecten la conservación de la tierra y la calidad del aire y del agua. Los planes deben concluir una justificación, previsión de sus efectos e identificación de los medios de ejecución. No deben ser incompatibles con las ordenanzas de conservación del agua y las políticas nacionales (ley de gestión de recursos naturales, sec. 63/67).

En España, los planes hidrológicos buscan satisfacer las demandas de agua, armonizar el desarrollo regional y sectorial, incrementar la disponibilidad de recursos, proteger su calidad y conservar y racionalizar el uso del agua en armonía con el entorno y demás recursos naturales. Los planes son obligatorios. Hay disposiciones detalladas sobre el contenido de los planes (ley de aguas española, 29/1985, arts. 35-44).

En los Estados Unidos varias leyes contienen disposiciones sobre la gestión integral del agua. La planificación es un elemento importante en los litigios entre estados por el recurso, así como en la aceptación de las limitaciones a las transferencias interestatales de agua.

La planificación de la tierra y el agua es elemento importante de las leyes sobre aguas limpias y agua potable pura. La ley nacional de política ambiental incluye varias exigencias de procedimiento para asegurar la consideración de los aspectos ambientales que se han aplicado a los proyectos hídricos. Se ha invocado esa ley para llevar ante los tribunales casos en que interviene el agua: construcción de presas y embalses, dragado y relleno, control de las crecidas, vertimiento en océanos, obras fluviales y portuarias y contaminación de humedales y del agua.
Otros requisitos de planificación, derivados de otras leyes, pretenden proteger las especies en peligro, los peces y la flora y fauna silvestres, los valores históricos y arqueológicos. La participación en los costos, el esparcimiento y los recursos hídricos afectados por las operaciones mineras figuran en otros decretos. Un principio importante es que los beneficios deben ser cuando menos iguales al costo de los proyectos, para que éstos sigan su curso (ley de recuperación de 1902, enmendada en 1939).

Aunque la ley de política ambiental no exige el análisis costo-beneficio, éste suele ser parte de la exposición sobre impacto ambiental, porque una de las. finalidades de la ley es considerar los servicios y los valores ambientales según criterios económicos. Los tribunales han pedido revisar la manifestación de impacto ambiental cuando el análisis de costo-beneficio se considera poco realista. Otros textos legales que exigen una ecuación costo-beneficio son la ley de control de crecidas de 1936 y la ley de protección de cuencas de 1954.

Hace más de 20 años el Consejo nacional de recursos hídricos de los Estados Unidos propuso un conjunto de principios y estándares para la planificación del agua y de los recursos naturales conexos, que constituye un buen ejemplo de evaluación multidisciplinaria de planes de recursos hídricos. Entre ellos se aconseja aplicar un sistema que muestra los beneficios o efectos adversos derivados de esos planes. Por consiguiente, el aprovechamiento del agua debe evaluarse según los efectos que distintos planes puedan tener sobre los objetivos del desarrollo económico nacional, la calidad del medio ambiente, el desarrollo regional y los factores sociales (Estados Unidos, Water Resources Council, 1971, pp. 24145-24146).

Hasta su modificación en 1983 los reglamentos exigían un análisis costo-beneficio. Se convirtieron en principios y directrices no obligatorios pero todavía insisten en el análisis económico. Las directrices no otorgan ningún derecho de procedimiento o sustantivo a parte alguna (Kelley-Pittman, 1991, pp. 299 y siguientes). Por lo tanto, el aspecto polémico del costobeneficio queda casi totalmente fuera del proceso de revisión judicial.

Respecto a América Latina, Dourojeanni señalaba la ausencia de criterios, principios y estándares de evaluación en la región, por lo que se aprueban proyectos con escaso análisis multidimensional (CEPAL, División de Recursos Naturales y Energía, 1995). No es pues extraño encontrar proyectos cuyo funcionamiento real o desempeño económico defraudan las expectativas de diseñadores, evaluadores y financistas. 
Las decisiones judiciales aportan también insumos de planificación importantes al derecho de aguas. Se ha podido identificar al menos un caso llevado ante los tribunales en que se solicitó una evaluación del impacto ambiental para otorgar subsidios de riego. ${ }^{5}$

\section{Capacidades de los organismos de gestión del agua}

Los organismos que se ocupan del agua y del medio ambiente tienen que competir por personal con el sector privado y con otros organismos en que están mejor pagados. Normalmente estos organismos cuentan con poco personal, formado en su mayor parte por ingenieros dedicados a soluciones estructurales y por abogados con escaso conocimiento del agua y sus dimensiones, fuera de la interpretación literal de la ley (Howe, 1996a).

En consecuencia, propenden a la inercia, lo que en un mundo cambiante es grave problema. Las consideraciones sociales, económicas y ambientales se conciben a veces como vallas que hay que superar y no como elementos de juicio provechosos.

Hay algunos conceptos modernos de gestión estratégica en el sector privado que deberían adoptarse cada vez más en el sector de gestión del agua. Su inclusión en este artículo pretende facilitar la evaluación inicial de capacidades, restricciones y posibilidades, con miras a poner en marcha procesos secuenciales y escalonados de mejoramiento de la gestión integrada del agua.

El sector privado presta especial atención a tres elementos en el diseño y ejecución de una estrategia: i) la industria (o actividad); ii) el país; y iii) los recursos, capacidades y estrategias disponibles que influyen en el desempeño de una unidad comercial o empresa.

Para aplicar este enfoque al ámbito de la gestión del agua, sería preciso:

a) Evaluar particularmente la actividad (en este caso la gestión integrada del agua) y su relativa madurez y consolidación en un país cuando se inicia o perfecciona un proceso de gestión integrada del agua. No se trata de despertar expectativas poco realistas al comienzo de los programas y proyectos, sino de establecer apropiadamente los puntos de referencia y las etapas en el desarrollo de un programa de gestión integrada.

\footnotetext{
${ }^{5}$ Natural Resources Defense Council v, Duvall, United Stales District Court, E.D. California, (777 F. Supp. 1533 E.D. Cal 1991) Asimismo, The New York Times, 1991.
}

b) Someter a evaluación el país en que se inicia un proceso o se somete a programas de perfeccionamiento. Si la capacidad nacional es en general limitada, sería exceso de optimismo suponer que el sector del agua podrá funcionar a un ritmo diferente del resto del medio socioeconómico. Nuevamente se trata de establecer objetivos y marcos cronológicos realistas y de identificar las esferas en que la puesta en marcha de procesos necesita un apoyo y refuerzo especiales.

c) Estrechamente vinculado con lo anterior está el hecho observado en varios países: programas de aprovechamiento de recursos hídricos iniciados sobre la base de los recursos de tierra y agua disponibles en el plano local, que prestan escasa atención a la solidez y sustentabilidad de la demanda de productos y bienes locales en que entra el agua como bien intermedio. Se desarrollan así inversiones estructurales costosas y rígidas sin un conocimiento cabal de la situación de la demanda y la competencia nacionales para caer en la cuenta, más avanzado el proceso, que tales inversiones no eran tan productivas como se había estimado. Actualmente, las buenas estrategias del sector privado se ocupan especialmente de las posibilidades y peligros en el plano nacional. El aprovechamiento económicamente sostenible del agua (integración entre el agua y la economía) debería incorporar este elemento de preocupación del sector privado.

d) Analizar los recursos, capacidades y estrategias disponibles para desempeñar la actividad. En numerosos países en desarrollo se espera que las instituciones encargadas del agua funcionen bien sin recursos humanos calificados, con fondos escasos y con estrategias mal definidas.

Las estrategias son el pivote para que las organizaciones de gestión del agua lleguen a la comunidad, ganen legitimidad y apoyo políticos y cumplan eficazmente su cometido. No es fácil definir qué es una estrategia adecuada. Además de los factores predeterminados - aunque manejables - relativos a la actividad, el país, los recursos y las capacidades, la confección de una buena estrategia exige conocimiento técnico, previsión, astucia política y buen liderazgo, aparte la convicción ética de que la eficiencia y la equidad en el uso y la distribución de los recursos hídricos son decisivas para la sustentabilidad. El requisito de la ética no siempre se aborda en la literatura sobre la gestión del agua, aunque goza de un lugar especial en la gestión moderna del sector privado (Hill y otros, 1996, p. 57).

En las estrategias hay que establecer metas básicas de largo plazo, trazar planes de acción conducen- 
tes a su logro y obtener y asignar recursos a los procesos de ejecución. Aunque este es el enfoque racional de la planificación, las estrategias también incluyen la reacción espontánea ante situaciones imprevistas de riesgo e incertidumbre. Es difícil el enlace entre los planes predeterminados y los imprevistos. La respuesta, lamentablemente muy simplista, sería que la planificación debe conservar la flexibilidad.

Dourojeanni, al referirse concretamente a la planificación de los recursos hídricos, sostiene que ésta debería centrarse de preferencia en lo que es posible y necesario (CEPAL, División de Recursos Naturales y Energía, 1995, p. 8). Traducido en términos opera- cionales, la planificación del agua requeriría medidas para preservar la sustentabilidad y satisfacer las necesidades humanas esenciales. Además, la planificación debe ser prudente para no comprometer recursos (financieros, naturales y humanos) en forma irreversible, para no causar inversiones estructurales rígidas con miras a satisfacer demandas mal estimadas o volátiles y para no enfocar la gestión desde el lado de las inversiones estructurales, descartando las medidas no estructurales como la gestión de ja demanda y la integración de la calidad y la cantidad del agua, el agua superficial y subterránea, y los recursos de tierras y aguas.

\section{III}

\section{El aprovechamiento y la gestión del agua debe inspirarse en un planteamiento basado en la participación de los usuarios, los planificadores y los responsables de las decisiones a todos los niveles}

1. Atribución de responsabilidades para la gestión integrada del agua

La organización funcional para la formulación de políticas, distribución y gestión del agua y vigilancia de los usuarios desempeña un papel importante en la puesta en marcha de un sistema sustentable de aprovechamiento. Cuando estas funciones se confieren a instituciones con responsabilidades funcionales por usos específicos del agua o por actividades económicas definidas, la gestión y la planificación del agua podrían no ser objetivas. En estos casos, cada parte interesada puede tender a apoyar proyectos o asignaciones de aguas según los intereses funcionales creados, sin atender a la fuente del suministro o a la solidez de las inversiones y proyectos.

Otra limitación es la separación entre las funciones de planificación y distribución del agua entre diferentes organismos, con lo cual se distancian la regulación de la planificación y se desligan los permisos de los planes (Dellapenna, 1991, p. 413 y siguientes).

Para soslayar esos problemas, varias jurisdicciones asignan la responsabilidad de la formulación de políticas, la distribución del agua y la evaluación de programas y proyectos a un organismo o ministerio no usuario independiente de los sectores tradicionales. Muchos países procuran mejorar la calidad de la toma de decisiones delegándola a niveles locales competentes y estableciendo acuerdos de coordinación entre los diferentes niveles de gobierno y también con el sector privado. En algunos casos la coordinación se da mediante la creación de organizaciones a nivel de cuencas integradas por las diferentes partes interesadas. Sin embargo, las organizaciones más sofisticadas conservan la coherencia mediante un sistema de aprobaciones y consultas de planes descentralizados elaborados por las autoridades regionales y a nivel de cuencas.

Otro mecanismo para mantener la coherencia consiste en retener cierta autoridad en manos de) gobierno central para aplicar la legislación que no hagan cumplir adecuadamente las organizaciones locales, regionales o de cuencas.

Brasil ha creado un sistema nacional de gestión de recursos hídricos para asegurar: a) la coordinación de la gestión integrada; b) el arbitraje administrativo de los conflictos; c) la ejecución de la política nacio- 
nal de aguas; d) el fomento de la tarificación del agua. El sistema comprende: a) un consejo nacional; b) consejos estaduales; c) comités de cuencas; d) organizaciones vinculadas con el agua en todos los niveles de gobierno; e) organismos de recursos hídricos (ley de política de aguas, 1997, arts. 32 y siguientes). La secretaría del Consejo Nacional de Aguas pertenece al Ministerio del Medio Ambiente y Recursos Hídricos (art. 45).

Francia creó una dirección de aguas en el Ministerio del Medio Ambiente, que recibe directrices de la Comisión Interministerial de Aguas, así como la Comisión Nacional de Aguas compuesta de usuarios, autoridades de cuencas y el gobierno, que expresa su opinión sobre asuntos relativos a la gestión nacional del agua. Sus actividades son descentralizadas y se ejecutan por conducto de las direcciones nacionales ambientales. El Ministerio supervisa las juntas de aguas de los organismos de cuencas fluviales en materias técnicas de gestión del agua. Las juntas son también responsables ante el Ministerio de Hacienda por su manejo financiero. El prefecto coordinador de la cuenca toma la iniciativa de preparar el plan de recursos hídricos de la misma, y está encargado de la ejecución y coordinación de las políticas estatales de gestión y fiscalización del agua. La dirección ambiental colabora con él. Los prefectos departamentales son el nivel administrativo básico de la intervención estatal en la gestión y fiscalización del agua, y en la preparación y seguimiento de los documentos de planificación. Asimismo, poseen facultades para actuar en casos imprevistos. Al nivel político más elementa!, las comunas tienen el monopolio legal del abastecimiento de agua potable y los servicios de saneamiento, están representadas en los comités de cuencas y en sus juntas de directores y cumplen un papel importante en la planificación de los recursos hídricos, ya que preparan planes de gestión y aprovechamiento del agua.

En Nueva Zelandia todos los niveles de gobierno están obligados a considerar ios efectos de las acciones propuestas sobre el medio ambiente. El Ministerio del Medio Ambiente retiene la facultad de aplicar toda disposición de la ley que no apliquen adecuadamente las autoridades locales correspondientes (Furuseth y Cocklin, 1995, pp. 243 a 272). Los consejos regionales preparan las declaraciones de principios y los planes regionales. Los consejos urbanos y distritales y los gobiernos de los territorios locales han perdido independencia en materia de planificación estratégica y gestión ambiental y se ha fortalecido la planificación regional en relación con la planificación ur- bana (Furuseth y Cocklin, 1995, pp. 263). Para asegurar la coherencia y la coordinación, las declaraciones de principios y los planes regionales tienen que ser consultados con el Ministerio de) Medio Ambiente, las autoridades locales y nacionales y las organizaciones maoríes (anexo 1, sección 3). Pese a la tendencia a delegar en el nivel intermedio (regional), el sistema cuenta con previsiones incorporadas en resguardo del interés nacional. El Ministerio del Medio Ambiente puede establecer estándares ambientales, llamar a consulta sobre obras polémicas, aprobar declaraciones de principios regionales y apelar de decisiones al tribunal de planificación. Además, el sistema en su conjunto está vigilado constantemente por el Comisionado Parlamentario del Medio Ambiente (Furuseth y Cocklin, 1995, pp. 266).

En España la autoridad suprema es el Ministerio de Obras Públicas y Urbanismo. El Consejo Nacional de Recursos Hídricos, integrado por todos los sectores interesados en el agua, tiene un papel consultivo y su función principal es opinar respecto al plan hidrológico nacional y a los planes hidrológicos de cuencas, que son aprobados por la legislatura y el gobierno, respectivamente.

Las cuencas fluviales son gestionadas por las confederaciones hidrográficas, reguladas y organizadas conforme al derecho público con un régimen jurídico diferente al del gobierno. Las confederaciones proponen el plan de gestión de cuencas, administran y controlan los recursos hídricos públicos; diseñan, controlan y administran las obras públicas; otorgan derechos y concesiones de aguas; inspeccionan y vigilan los recursos hídricos, sus usos, y las obras hidráulicas; miden los recursos hídricos; estudian la situación de los recursos hídricos; mantienen registros de las crecidas y proporcionan información al respecto; controlan la calidad del agua y prestan servicios técnicos (Cubillos, 1994, p. 28).

Pese a estos indicios de mayor coherencia e independencia en el ámbito de la gestión de los recursos hídricos, en varios países, provincias o estados de una federación, los componentes del agua están fragmentados entre los organismos de gestión que se ocupan de problemas de la calidad y cantidad del agua y otros encargados del agua superficial y subterránea (Mitchel (ed.), 1989, p. 203).

\section{Participación de los interesados y protección de los intereses públicos}

Existe un proceso para democratizar y equilibrar la toma de decisiones en materia de recursos hídricos y 
actividades conexas. Para la planificación del agua es importante una participación equilibrada, informada y pluralista, porque fomenta la consideración de una amplia gama de aspectos y con ello toma en cuenta las diferentes dimensiones del recurso. Esta se da mediante consultas públicas, participación de los interesados en órganos administrativos, organización de las asociaciones de usuarios y, respecto a las preocupaciones ambientales generales, con una mayor permisividad en las normas que rigen el derecho de las partes para actuar en foros administrativos o judiciales. Así, los interesados pueden participar en la formulación de políticas, el debate legislativo, la administración general de aguas y las actividades en el terreno.

La ley de gestión de recursos naturales de Nueva Zelandia prescribe la realización de consultas públicas para discutir, entre otras cosas, los planes de gestión de recursos y la concesión de autorizaciones en materia de recursos. Estas consultas no deben complicarse con formalidades innecesarias (art. 39). El derecho a ser oído y a presentar pruebas se basa en el prestigio general de las partes interesadas, limitándose la participación de las partes que tengan el mismo interés (secc. 40).

Algunos países han asumido compromisos muy firmes de considerar los intereses y derechos de aguas de las comunidades aborígenes y los usos tradicionales. Nueva Zelandia, Canadá, los Estados Unidos y algunos países del Pacífico Sur (Fiji, Papua Nueva Guinea) ofrecen ejemplos muy valederos. La consideración de los intereses maoríes en Nueva Zelandia es un principio básico del proceso de planificación.

Sin embargo, en algunos casos los intereses e inquietudes de las poblaciones locales no han sido prioritarios al planificar el aprovechamiento del agua. La indiferencia por los derechos tradicionales se ha identificado como uno de los factores principales de los conflictos vinculados con los esfuerzos de desarrollo y con su falta de éxito en algunas partes del mundo. También se ha manifestado inquietud por el descuido de los valores e intereses sociales vinculados con el agua. ${ }^{6}$

Los usuarios y otros interesados en el recurso pueden participar en audiencias o consultas públicas destinadas a analizar políticas, programas, proyectos o legislación. Aunque el mecanismo se destina fundamentalmente a abrir espacios de participación, su sola

* Véase, en general: Coñac, 1989, así como los planteamientos de Barraqué, 1997. creación no significa que vayan a participar todos los interesados, asegurando con ello un equilibrio de intereses o decisiones más racionales. Así, cuando el Reino Unido regionalizó la gestión del agua en 1974, ciertos grupos de presión influyentes recibieron un trato más favorable en perjuicio de la apertura al público y, según algunos, de la eficiencia económica (Barraqué, 1992, p. 9). Mitchel comparte esta apreciación y percepción y señala que a medida que las autoridades regionales de recursos hídricos se han reformado para darles un corte más empresarial se ha dejado de involucrar al público en las decisiones reales (Mitchel (ed.), 1989, p. 215).

Kemper, en su excelente análisis del Valle de Curú, en el estado de Ceará, Brasil, observa que los grupos usuarios privilegiados ocupan una posición dominante en el valle, tienen un grado más alto de instrucción, están mejor organizados, y serían poderosos en las negociaciones colectivas destinadas, por ejemplo, a mantener bajas las tarifas del agua. Estos grupos que comprenden a los grandes complejos agroindustriales y latifundios, tienen más influencia que los campesinos más pobres. En cambio, los usuarios más pobres tienen que acatar las reglas del clientelismo político (Kemper, 1996, pp. 195 a 200). La autora cita también a Hearne y Ester para concluir que la estructura legal de los mercados de aguas en Chile ha derivado en la concentración, en grandes empresas fruteras exportadoras, de los derechos de tierras y aguas decomisados, y que aunque mejoró la eficiencia económica no habría mejorado el bienestar general (Kemper, 1996, p. 193 y Hearne y otros, s.f.).

Ejemplos similares, en que las decisiones podrían haber sido dictadas por grupos de presión dedicados a la construcción, la urbanización y la agricultura y no necesariamente inspiradas en la racionalidad económica o el bienestar económico general, se dan en otras partes de América Latina. Hace poco un informe estimó que la viabilidad económica de una presa en el oeste de Argentina estaba "muy comprometida"; el gobierno obtenía en la mayoría de los casos un beneficio neto negativo. El proyecto no era económicamente atractivo, ni en términos de viabilidad general ni en términos de beneficios derivados de la inversión pública. Intereses especiales habían lanzado una activa campaña a favor del proyecto. El informe citado no fue difundido. Las repercusiones que tiene para el país la inversión pública no rentable (y el endeudamiento público previo) en relación con los impuestos y el gasto no son bien entendidas por el público en general. Al parecer en virtud de una decisión política reciente el 
proyecto se construirá (Argentina, Ministerio de Economía y Obras y Servicios Públicos, Subsecretaría de Energía, 1997, p. 5 y portada).

Personeros del UNICEF han señalado el peligro de que grupos de intereses creados monopolicen el agua en nombre del crecimiento, y que la desigualdad siga aumentando. $^{7}$

Sin embargo, hay casos positivos de participación de los interesados. En la cuenca fluvial de Yahagi, Japón, una asociación de protección de la calidad del agua ha mostrado cómo los diversos grupos del sector privado pueden aunar sus intereses y capacidades para abordar problemas que en muchos países se dejan librados al sector público (Mitchel (ed.), 1989, p. 305).

Otros ejemplos de participación positiva son las asociaciones profesionales. La Sociedad Estadounidense de Ingenieros Civiles trabaja activamente en la preparación de principios jurídicos para el fomento de la gestión y la planificación integradas. Partiendo de la premisa de que el agua se beneficia de los procesos de gestión y planificación, ha bosquejado un conjunto de principios básicos que deben incorporarse al derecho de aguas para promover una mejor gestión: a) con algunas excepciones, toda el agua es un bien público; b) la calidad y la cantidad del agua no pueden separarse; deben integrarse las aguas superficiales, subterráneas y atmosféricas; c) 'entre las facultades del sector público necesarias para una buena gestión debe figurar la de realizar evaluaciones multifacéticas de las asignaciones y transferencias de agua; d) los derechos pueden perderse por derroche; e) los derechos de agua pueden revaluarse periódicamente y la función del agua puede variar según los cambios tecnológicos; f) la planificación integral exige equilibrar los intereses públicos y privados; g) deben estimarse los rendimientos seguros y los caudales mínimos necesarios para mantener la calidad del agua y proteger la biodiversidad, una vez identificados los usos existentes; h) hay que elaborar estrategias para casos de sequía y pueden crearse zonas especiales de gestión del agua; i) deben establecerse sistemas para solución de diferencias y procedimientos de arbitraje; j) deben otorgarse facultades apropiadas de coacción y ejecución a los organismos pertinentes; $\mathrm{k}$ ) hay que reconocer la necesidad de lograr el desarrollo económico fomentando la efi-

\footnotetext{
${ }^{7}$ Gourisanker Ghosh, Jefe del Módulo Medio Acuático y Saneamiento, UNICEF, N.Y., discurso principal formulado en la vigésima segunda conferencia WEDC, Nueva Delhi, 9 a 13 de septiembre de 1996.
}

ciencia económica, al exigir asignaciones razonables y reconocer los derechos existentes; 1) es preciso proteger los valores ambientales ampliando el concepto de uso beneficioso; $\mathrm{m}$ ) debe fomentarse la conservación y el aumento del recurso otorgando permisos para las aguas conservadas; $n$ ) es preciso reducir los costos de transacción en las transferencias temporales (Matthews, 1994).

Se sostiene que los gobiernos pueden estimular la capacidad de las partes interesadas dándoles acceso a datos, autorización para actuar en reuniones y, en general, posibilidad de expresar opiniones y posiciones (Haddad, 1996, p. 392).

La necesidad de fomentar el papel activo que debe representar el gobierno en promover la participación parece confirmarla en la práctica una experiencia reciente de Sudáfrica: en una consulta pública sobre la próxima legislación de aguas, las industrias entregaron respuestas amplias y varias organizaciones e individuos respondieron también en forma positiva. En cambio, no formularon observaciones ni las organizaciones comunitarias ni las comunidades rurales o los comités de aguas a nivel de aldea. Los organismos no gubernamentales hicieron muy pocos comentarios.

La cuestión de la participación se relaciona estrechamente con el dictado y aplicación de las leyes, así como la responsabilidad ante ella. Siendo que la acción del gobierno representa el medio tradicional de creación y aplicación de la ley, es un grave problema actual la inercia del gobierno en esta materia. Esta inercia puede derivarse de la incapacidad para actuar, de la falta de recursos, o de la ausencia de voluntad para decidir entre presiones contrapuestas.

Un buen ejemplo de creación en materia de jurisprudencia en la esfera ambiental, en que se ha ampliado el campo en que los ciudadanos pueden apelar ante la ley con una mayor flexibilidad para habilitar la acción de grupos o individuos con intereses distintos de los económicos personales tradicionales.

Sin embargo, los recursos ciudadanos son limitados cuando no hay marcos jurídicos que posibiliten la acción pública. A su vez, la existencia de esos marcos se ve afectada por las diferencias de posibilidades de acceso a los que toman las decisiones políticas y la capacidad de cabildeo de grupos de presión con intereses distintos. Si bien varios países han promulgado normas sobre el medio ambiente y los impactos ambientales, los reglamentos de evaluación económica y condicionamiento de los proyectos por motivos económicos, recurribles por el público o por terceros, son escasos o nulos. Incluso los proyectos más deficientes 
no pueden ser cuestionados por los miembros del público por motivos económicos. En este sentido, el público de la mayoría de los países está limitado por dos factores: la falta de reglas sustantivas obligatorias para evaluar la eficiencia económica de la inversión pública y los estándares y umbrales conexos y, por ende, la existencia de normas rígidas que sólo otorgan "legitimación sustancial activa" para actuar en defensa de los derechos económicos personales tradiciona$\operatorname{les}^{8}$. Algo parecido ocurre con los intereses sociales. El caso de la presa en la Argentina occidental, citado anteriormente, ofrece un buen ejemplo de esta situación. Otra consideración es que los grupos de cabildeo exitosos no tienen que rendir cuentas.

La participación y el acceso disparejos de los interesados parecen ser un motivo de preocupación internacional. Un proyecto en América Latina, ejecutado por Consumer's International (financiado por la United Kingdom Overseas Development Administration), parte de la premisa de que los intereses de los consumidores no están bien representados en los procesos normativos que regulan los servicios de utilidad pública de agua, electricidad y teléfono en América Latina. Esto obedece a las barreras institucionales creadas por los gobiernos así como a la falta de información y conocimientos técnicos entre las organizaciones de consumidores.

\section{La información}

La necesidad de datos e información pública no es sólo un factor condicionante de una toma de decisiones apropiada, sino un medio eficaz de contener desequilibrios. Para ser eficaz, un sistema participativo de planificación y gestión de los recursos hídricos tiene que ser capaz de suministrar información oportuna sobre qué clase y calidad de agua está disponible, dónde, y quién la utiliza y para qué fines. Por lo tanto, los sistemas eficientes de gestión del agua requieren encuestas, inventarios y catastros oficiales adecuados

\footnotetext{
${ }^{8}$ E! término técnico "legitimación sustancial activa" (standing) se refiere al derecho de entablar una acción judicial en los tribunales. Tradicionalmente, sólo se otorgaba categoría para actuar atendiendo a intereses económicos individuales, es decir, no ampliamente compartidos, excluyendo otros intereses como los valores estéticos y recreativos. Si bien este concepto está cambiando rápidamente, en la mayoría de los países los ciudadanos no tienen derecho a apelar alegando que los gobiernos han adoptado decisiones económicas malas o inadecuadas. Se trataría de un interés altamente disperso, y por lo tanto no suficientemente fuerte, ante la falta de legislación expresa, para otorgar el derecho a actuar en tribunales.
}

de las fuentes y del abastecimiento de agua, así como de registros actualizados de los usos y de las descargas, los derechos de agua, y los beneficiarios de esos derechos, con sus respectivas asignaciones. Es por esta razón que, en los sistemas de gestión de agua bien desarrollados, habitualmente se cobra por los derechos de agua, a fin de financiar los gastos de información y gestión administrativa,

El objeto de la información es permitir que los responsables de la política, administradores, gerentes, usuarios y el público tomen decisiones apropiadas.

La ley de aguas brasileña de 1997 incluye específicamente la información entre los instrumentos para ejecutar la política nacional de recursos hídricos (art. 5). El sistema opera sobre la base de la descentralización, la coordinación unificada y el libre acceso a los datos (art. 26).

La ley de recursos hídricos de 1991 del Reino Unido dispone que la autoridad fluvial nacional proporcione información a los encargados de la política y empresarios y también al público (seccs. 196-197). Por su parte, la autoridad está facultada para obtener información sobre el agua superficial y subterránea. La información debe ser oportuna y adecuada, y hay disposiciones sobre la clase de información que debe recopilarse y la manera en que debe organizarse (seces. 197-203). El sistema británico está complementado con normas sobre la información confidencial y reservada y sanciones por declaraciones falsas (205-206). La participación pública se procura mediante un sistema de encuestas (seccs. 213-215).

La ley de aguas de Canadá establece programas de información pública en virtud de los cuales se instruye a la población acerca de la conservación, aprovechamiento y utilización del agua (art. 27). La ley estipula asimismo que el ministro encargado del recurso informe cada año fiscal al parlamento sobre las operaciones realizadas en virtud de dicha ley (art. 36).

La ley de gestión de recursos de Nueva Zelandia ordena a las autoridades locales y las redes de servicios de utilidad pública que proporcionen información al Ministro de Medio Ambiente (sec. 27). Las autoridades locales deben recopilar información y mantener registros sobre diversos aspectos que incluyen, entre otros, planes, autorizaciones en materia de recursos y, quejas (sec. 35). Los estándares nacionales en materia de calidad, niveles o caudales no pueden someterse a aprobación sin que antes la opinión pública tenga ocasión de formular sus comentarios, a fin de que éstos se incluyan en las presentaciones, sin que el informe y sus recomendaciones hayan sido publicados aún (sec. 44). 
Las propuestas para enmendar la ley de aguas española de 1985 incluyen el derecho del público a acceder a la información relacionada con el recurso (art. 13 bis).

La ley de investigación de recursos hídricos de 1964 (EE.UU.) estableció institutos de investigación de los recursos hídricos en cada estado. Su labor, según Beck y Goplerud (eds.) (1991), ha contribuido notoriamente a la base de datos disponible para la planificación federal y estadual.

\section{El nivel adecuado más elemental posible}

En general, se reconoce que la cuenca fluvial sería la unidad más apropiada para aplicar las estrategias en materia de recursos hídricos. Sin embargo, suelen trazarse círculos arbitrarios en torno a los proyectos hídricos, descuidando los impactos externos. Las fronteras jurisdiccionales que no corresponden al río o a otros sistemas naturales son una de las mayores causas de ineficiencia en el diseño y operación de los sistemas hídricos. En general, se suelen descuidar los impactos fuera de la jurisdicción (Howe, 1996a, pp. 31 y 32).

Por esta razón, el profesor Howe sostiene que el concepto de subsidiariedad (el nivel adecuado más elemental posible para la aplicación y ejecución de políticas) puede aumentar la probabilidad de importantes externalidades, dado que el nivel político adecuado más elemental posible no siempre coincide con los límites naturales. La tensión entre la subsidiariedad y las externalidades es uno de los problemas pendientes más graves del diseño de políticas (Howe, 1996a, p. 32).

La organización adecuada a nivel de cuencas permite disminuir o reducir los costos de transacción. Por lo tanto, algunos países han aumentado la importancia política de las cuencas fluviales. En Nueva Zelandia la cuenca es no sólo la unidad de planificación y gestión del agua sino también el centro principal de los consejos regionales, responsables principales de la gestión sustentable. Los consejos responden por el aprovechamiento del agua y la conservación del agua y del suelo, los recursos geotérmicos, el control de la contaminación y la reducción de los peligros en el plano regional (Furuseth y Cocklin, 1995, pp. 243 a 272). En forma más concreta, controlan el uso, aprovechamiento, embalse y descargas del agua (sec. 30, ley de gestión de recursos).

La ley incorpora la flexibilidad al autorizar las transferencias y delegaciones de funciones de las au- toridades locales en otras entidades. Sin embargo, las transferencias y delegaciones están sujetas a aprobación y deben fundarse en la eficiencia, los conocimientos técnicos y la representación del nivel comunitario (seccs. 33-34).

En forma similar, según Barraqué, los Países Bajos han transformado las organizaciones de cuencas en autoridades locales (Barraqué, 1992, p. 21).

No obstante, la necesidad de asegurar que las organizaciones de cuencas realicen todo su potencial en términos técnicos para reducir los costos transaccionales, no ha cegado a los países respecto a la necesidad de que el público y los interesados participen. Por lo tanto, en Francia las organizaciones de cuencas fluviales procuran asegurar la participación adecuada de las partes afectadas e interesadas.

Asimismo, mediante la creación de la figura del prefecto coordinador, las reformas recientes de la ley de aguas francesa parecen evolucionar hacia un mayor acercamiento entre las autoridades administrativas y las organizaciones de cuencas. Los organismos de cuencas fluviales franceses están basados en el ámbito geográfico de la cuenca, sin tomar en cuenta los territorios políticos, en un intento por escapar a la lucha política. El enfoque de gestión se basa en un contrato suscrito entre los grupos interesados sobre una base descentralizada. Las metas concretas incluyen aumentar la calidad y cantidad del agua. El sistema integra la gestión y privatización del agua. Los usuarios deben pagar por la contaminación y las aguas servidas. Las juntas de los organismos tienen representación tripartita (gobierno central, gobierno local y otros usuarios). Los organismos están (ahora) plenamente legitimados ante la opinión pública (Barraqué, 1992, p.21).

El funcionamiento de los organismos franceses de cuencas fluviales ha merecido algunas criticas por su dependencia excesiva de un método de compromisos y también por las deficiencias en la planificación integrada de los recursos hídricos y la falta de facultades fiscalizadoras claramente definidas (Barraqué, 1992, pp. 13, 20 y 21). Lo interesante es que estos reparos son los mismos que podrían hacerse a las tentativas de crear instituciones de cuencas lluviales en América Latina,

La ley de reforma agraria del Perú de 1991 dispone la creación de autoridades de cuencas independientes para promover la formulación de planes maestros y fomentar su ejecución dentro de su zona de juris- 
dicción. Su éxito ha sido relativo, por falta de recursos, de atribuciones bien definidas y de marcos organizacionales.

La cuenca también ha sido el centro de varias actividades con patrocinio nacional e internacional en el ámbito nacional y proyectos transfronterizos en Africa, Asia y América Latina. Estos programas han enfrentado restricciones y se han criticado, entre otras cosas, por falta de correspondencia con las capacidades de la zona en cuestión, mandatos demasiado amplios - y al mismo tiempo débiles_-, incapacidad para tratar con las jurisdicciones políticas tradicionales, desconocimiento de los problemas ambientales, perturbación de las modalidades locales de producción, insensibilidad frente a las realidades y condiciones sociales en el lugar de ejecución, falta de recursos e incapacidad de prever los efectos a largo plazo.

Una limitante fundamental de estos proyectos ha sido la falta de propietarios locales, y, como consecuencia, un escaso apoyo político y electoral, que de hecho puede ser el aspecto clave para el éxito, o fracaso, de las organizaciones de cuencas.

\section{IV}

\section{El agua tiene un valor económico en todos sus diversos usos en competencia a los que se destina y debería reconocérsele como un bien económico}

\section{Derechos de agua}

Aunque el agua posee valor económico y los derechos de agua ofrecen seguridad de su tenencia a los usuarios del recurso, hay en general una tendencia a condicionar su uso. Entre las condiciones figuran requisitos formales (obtener un permiso) y de fondo (por ejemplo, no perjudicar a terceros, protección ambiental, eficiencia).

Según la ley brasileña el sistema de derechos de agua es uno de los instrumentos para hacer cumplir la política nacional de recursos hídricos (ley de 1977, art. 5).

En Nueva Zelandia, las autorizaciones para hacer uso del agua están reguladas por la ley de gestión de recursos. Las autorizaciones (resource consents) no pueden infringir los términos de los planes de gestión de recursos. Se exige la descripción de la actividad y el lugar, así como la evaluación del impacto ambiental (sec. 88). Las autorizaciones se otorgan tomando en consideración, entre otras cosas, políticas y planes (sec. 104). Pueden estar sujetas a cobros, fianzas, pactos, contribuciones financieras, obligaciones de información y responsabilidad legal por daños ambientales (incluso después de haber expirado). (108). Las auto- rizaciones están sujetas a revisión si hay impactos ambientales adversos o se estructuran nuevos planes (sec. 128). Además, el tribunal de planificación puede modificar o cancelar una autorización por orden ejecutiva (133).

Resulta interesante comparar Nueva Zelandia con Chile, donde el sistema es uno en que casi todas las aguas son de propiedad pública, pero el sistema de derechos ha resultado en una suerte de privatización funcional.

En Chile, la asignación de aguas no está relacionada con ningún uso o precio específico. Si hay agua disponible el gobierno no puede, según el código de aguas, rechazar una solicitud (Peña, 1996, p. 7). Una vez asignado el recurso la única regulación posible está dada por el mercado del agua. Un informe reciente sostiene que los resultados del sistema comprenden: a) la transferencia gratuita de la riqueza pública (Peña, 1996, p. 10); b) las solicitudes actuales de asignación de agua ascienden a $50000 \mathrm{~m}^{3} / \mathrm{s}$, es decir, el cuádruple del volumen total explotable disponible en el país y sin ninguna relación con el desarrollo nacional previsto durante los próximos 50 años (Peña, 1996, p. 10); c) la situación distorsiona la operación del comercio del agua y otros mercados, puesto que algunas indus- 
trias pueden utilizar los derechos de agua como disuasivo al ingreso de terceros en actividades competitivas; ${ }^{9}$ d) los resultados pueden incluir la subinversión y alzas de precio de productos como la electricidad; e) además, la estructura individualista del sistema de derechos de agua no deja espacio para la planificación de mediano y largo plazo (Peña, 1996, p. 12); f) las externalidades de largo plazo son difíciles, por no decir imposibles, de controlar; g) la gestión integrada de cuencas es limitada ya que los ríos están divididos, para fines administrativos, en secciones que no representan unidades hidrológicas; h) el agua subterránea y superficial se gestionan en forma independiente; i) la calidad y cantidad no están integradas y el aprovechamiento del agua no está planificado conforme a objetivos de uso múltiple, sino sectorialmente (Peña, 1996, p. 15).

La ley de aguas alemana, que ofrece un buen ejemplo de tendencias, anexa varias condiciones al uso, los permisos y las licencias del recurso. Comprenden, entre otras cosas, la posibilidad de imponer nuevas condiciones después de la concesión del permiso o licencia. Las condiciones expost pueden referirse a los requisitos ambientales o económicos de la gestión de los recursos hídricos (art. 5). El uso de agua por los dueños de predios y las poblaciones ribereñas no debe afectar a otras personas, ni provocar cambios perjudiciales del agua, alterar el balance hídrico, o reducir notoriamente los caudales (art. 24).

La ley de aguas española dispone que los derechos de agua se otorguen según las disposiciones de los planes hidrológicos (art. 57, ley 29/85). Los derechos de agua se ajustarán y revisarán según lo requieran los cambios de los planes hidrológicos (art. 63, ley 29/85).

\section{Mercados del agua}

Se presta cada vez más atención a la comercialización de los derechos de agua como una alternativa provechosa y económicamente eficiente para mejorar la distribución del recurso.

\footnotetext{
${ }^{9}$ Tres decisiones han considerado la relación existente entre los derechos de agua y la monopolización: 1) Tribunal de Apelaciones de Puerto Montt, Endesa versus Dirección General de Aguas, 31 de enero de 1997; 2) Comisión Preventiva Central: Consulta del Ministro Presidente de la Comisión Nacional de Energía, Res CPC 992/636/25/11/96; y 3) Comisión Resolutiva, Resolución N" 480; $7 / 1 / 97$.
}

Sin embargo, hay países como China, que sin dejar de reconocer la necesidad de desarrollar los mercados del agua, ponen de relieve la necesidad de una gestión general de los recursos hídricos para evitar impactos perjudiciales sobre el medio ambiente y el desarrollo social.

Un resultado de las complejidades de la comercialización del agua es que la actividad ha estado sujeta a regulaciones en el interés de terceros y del público (Anderson y otros, 1991, pp. 234 y siguientes).

Asimismo, hay criterios de interés público que se aplican a la revisión de las solicitudes para transferir derechos de agua. Se aplican a la revisión de las externalidades de valor público y comprenden: a) efectos sobre la actividad económica resultantes de la solicitud; b) efectos sobre la pesca y la caza y sobre el esparcimiento público; c) efectos sobre la salud pública; d) costo de oportunidad del uso; e) daños a otras personas; f) intención y capacidad de uso; g) efectos sobre el acceso a aguas públicas y navegables; h) necesidades de conservación del agua; i) factores de importancia local.

En consecuencia, no se permitiría la reasignación si ésta resultara en la violación de estándares mínimos de salud, medio ambiente o seguridad. Sin embargo, se puede cumplir el criterio de interés público si se condiciona la solicitud de reasignación a medidas que lo satisfagan.

Aunque no se cuestiona la legitimidad sustantiva de los asuntos de interés público, se han planteado interrogantes acerca de los foros y medios apropiados para tratarlos. Siempre existe una función administrativa y judicial, pero para algunas autoridades tales medios y foros deberían incluir la planificación del agua y la participación pública. ${ }^{10}$

Otras consideraciones incluirían la evaluación de los impactos que pueda tener una transferencia sobre el ambiente, la base tributaria o la economía local de la zona de origen de la asignación de agua que va a transferirse.

Se ha sugerido que la comercialización de recursos hídricos debería sujetarse a un programa, es decir, a una gestión activa con metas mensurables y puntos de referencia e incentivos por desempeño según calendario (Haddad, 1996, p. 392).

\footnotetext{
${ }^{10}$ Véanse Dumars y Minnis, citados por Anderson, 1991, p.298, asi como New Mexico Statutes. Ann: 72-14-1; 72-14-22.
} 


\section{Gestión integrada del agua, incentivos econó- micos y cobros}

En general, se acepta que la fijación de precios es un instrumento apropiado de la gestión del agua.

Al menos una ley (Brasil, 1997) identifica el cobro del agua como uno de los instrumentos para ejecutar la política nacional de recursos hídricos (art. 5), El cobro del agua reconoce la dimensión económica de los recursos hídricos, da a entender al usuario el valor real del recurso, promueve la racionalización del uso del agua y asegura recursos financieros para cubrir los costos de los programas y proyectos incluidos en los planes de recursos hídricos (art. 19). Los fondos allegados mediante el cobro del agua están destinados sobre todo a asignarlos a la cuenca que los generó. Están destinados a pagar los costos de aplicación de los planes de cuencas y a cubrir los gastos del sistema administrativo. Tales gastos no pueden sobrepasar el $7.5 \%$ de los fondos totales recaudados.

En Francia, los organismos encargados del agua (Agences de l'Eau) ofrecen incentivos financieros para el mejoramiento y la preservación de los recursos hídricos. Los usuarios pagan una tarifa basada en los volúmenes de agua consumida o en los volúmenes de contaminación causados. Con posterioridad, las sumas recaudadas se reinyectan al sector a fin de colaborar con el sector público y privado en el pago de la conservación del recurso y de las instalaciones, equipo y tecnologías anticontaminantes.

Las medidas financieras se incorporan en programas plurianuales (generalmente quinquenales), presentados a los comités de cuencas, y aprobados por el Primer Ministro, previa recomendación de la Comisión Interministerial de Aguas, Los usuarios que pagan las tarifas e integran los comités de cuencas votan los programas de acción.

Los programas de acción deben ser compatibles con las políticas socioeconómicas nacionales y la política general de aguas. Comprenden tres secciones: identificación y análisis de problemas; acciones, costos y estimación de la asistencia prevista por parte de las juntas de aguas; sistemas tarifarios (ingresos previstos) a fin de asegurar el equilibrio financiero del sistema.

Las tarifas se cobran a toda persona pública o privada que extraiga agua, la contamine o altere su régimen, y que se beneficie de las obras construidas con la asistencia de las juntas de aguas. Las ciudades, las industrias, los agricultores y la generación de electricidad pagan tarifas.

La ley de gestión de recursos de Nueva Zelandia estipula que el Ministro debe considerar e investigar el uso de instrumentos económicos para lograr los fines que persigue la ley (Ley de 1991, sec. 24h). Asimismo, el Ministro puede otorgar donaciones y préstamos para fomentar los fines que persigue la ley (sec. 27). Las autoridades locales están facultadas para fijar tarifas, las que pueden ajustarse según el costo real y recuperarse del beneficiario de la actividad, lo que no es obligatorio para la autoridad hasta el pago íntegro de la misma (sec. 36). La relación entre medios y arbitrios está claramente establecida por la ley, la que en la sección 38 relaciona los funcionarios ejecutores con el pago de salarios y gastos. La sección 112 también se ocupa de otros ingresos, pues dispone el pago de regalías y alquileres a los consejos regionales.

En el Reino Unido, los servicios de abastecimiento de agua potable y saneamiento deben pagar cierta suma para contribuir al pago de los costos de la autoridad fluvial. Las facultades de la Comisión Federal Reguladora de Energía de los Estados Unidos incluyen el cobro por el uso de la propiedad pública.

La cuestión de cobrar por el agua no está en modo alguno libre de polémicas. Las propuestas de cobrar por el agua han sido objetadas por los servicios de utilidad pública chilenos, que alegan que los derechos de agua originales se otorgaban gratis y que todo cobro ulterior afectaría los derechos de propiedad. En Suiza, el departamento de aguas de los servicios industriales de Ginebra resiste la tentativa del gobierno cantonal de introducir un impuesto al agua para pagar la recuperación de ios ríos del cantón (Financial Times, 1996, pp. 3 y 4$)$. 


\section{V}

\section{Conclusiones}

\section{La ética en la gestión integrada del agua}

La gestión integrada sustentable del agua está condicionada, entre otros factores, por la eficiencia y la equidad. La gestión y la distribución ineficientes de los recursos tienen consecuencias negativas para la equidad (considerando los grupos beneficiarios desfavorecidos) puesto que limitan los beneficios y el acceso al agua.

La eficiencia y la equidad en la gestión integrada del agua se relacionan estrechamente con el buen gobierno y, en último término, con la ética. El concepto de ética en este contexto implica: i) no financiar los proyectos públicos con una tasa de rendimiento negativa, a menos que esté justificado por consideraciones sociales indiscutibles, debidamente expuestas y comprobadas; ii) brindar a la opinión pública información exacta, precisa y transparente; iii) no emprender proyectos públicos sin evaluar cuidadosamente las repercusiones económicas, sociales y ambientales; iv) no permitir la manipulación y monopolización del recurso por parte de intereses especiales.

\section{Capacidades de los organismos de gestión del agua}

Hay sistemas en que la planificación se entiende sobre todo como el desarrollo ordenado de las obras hidráulicas. Hay otros que incluyen consideraciones explícitas de bienestar social, eficiencia económica, evaluación de alternativas —incluso opciones no estructurales y no actuar-impactos sociales y consideraciones detalladas de los efectos ambientales. Aunque el primer enfoque puede asegurar el orden y la precisión así como la corrección técnica, necesita complementarse con el segundo criterio a fin de llegar a un conocimiento cabal de la situación general y a una toma de decisiones atinadas.

Aunque algunos de los ejemplos nacionales analizados en el presente informe indican que están relativamente bien desarrolladas las disciplinas de la gestión y la planificación integradas del agua, es dispareja la incorporación de las normas técnicas en disposiciones legales obligatorias, si se analiza la situación en el plano mundial.
En qué medida los países rezagados podrán mejorar su gestión de los recursos dependerá de la capacidad de cada país. Los programas de formación de capacidades pueden contribuir a remediar situaciones particulares, pero a la postre su éxito dependerá del compromiso nacional y la propiedad nacional de los recursos.

La formación de capacidades en este contexto incluye no sólo personal idóneo, recursos financieros suficientes y una organización adecuada, sino el soporte lógico para una buena evaluación de proyectos.

Algunos sistemas nacionales de gestión del agua incorporan principios para la evaluación de proyectos, programas, o incluso legislación y políticas. Aunque los últimos adelantos en materia de evaluación comprenden principios bien elaborados sobre cuestiones ambientales, económicas y sociales, las normas sustantivas y de procedimiento con fuerza legal son más estrictas en materias ambientales que en cuestiones económicas y sociales. Por ello, en algunos países el público y el sector privado tienen un grado relativamente mayor de flexibilidad y de posibilidades de acción respecto de las cuestiones ambientales que en los asuntos vinculados con la eficiencia económica, la equidad social y la racionalidad de las acción pública relacionada con el agua.

La mayoría de los países en desarrollo carecen de normas apropiadàs para la evaluación obligatoria de los efectos económicos, sociales y ambientales de los proyectos de agua.

La gestión y la planificación integradas del agua se apoyan en un abanico de atribuciones legales públicas y conocimientos técnicos. Sin embargo, su puesta en práctica en los países en desarrollo se ve obstaculizada por una limitada capacidad de aplicación y un marco jurídico insuficientemente desarrollado, así como escasa información y conocimiento sobre la dinámica del recurso y un acceso e influencia desproporcionados de los grupos especiales de interés.

En cuanto a la capacidad de llevar adelante la planificación integrada del agua, preocupa la separación entre la planificación y la regulación. Los países están tomando medidas al respecto. Algunos concentran la capacidad planificadora y reguladora en instituciones no sectoriales, otros crean al mismo tiempo nuevos me- 
canismos de coordinación e integración institucional, y hay un grupo en que se da la integración de la gestión a nivel de cuencas, mediante la delegación de funciones en las autoridades regionales o de las cuencas. La delegación va acompañada de procesos de escrutinio y consultas de los planes regionales y de cuencas a nivel nacional y el gobierno central conserva algunas facultades en sus ministerios para corregir la falta de aplicación o la aplicación descuidada de leyes y políticas, así como para asegurar la coherencia.

La creación de consejos nacionales para conciliar y armonizar diferentes instituciones está ganando terreno, pero algunas experiencias indican que el proceso podría obstaculizarse por efectos de las contiendas políticas, la aplicación de normas de procedimiento deficientes y la necesidad de obtener legitimidad.

Existe un acuerdo explícito de que la cuenca es la unidad más adecuada para la gestión integrada del agua. Al mismo tiempo, interesa que el concepto se exprese explícitamente al aplicar el principio del nivel más elemental posible. Preocupa además la aplicación del concepto de cuenca frente a las fronteras jurisdiccionales. Las alternativas existentes derivadas de modelos, principios legales y acuerdos organizacionales para superar las fronteras políticas (tales como la utilización equitativa, la prohibición de perjuicio grave) y las facultades de los gobiernos nacionales en países federales exigirían entonces más investigación y difusión. En definitiva, la importancia técnica de la cuenca y la capacidad de las organizaciones encargadas de ella para reducir las externalidades y los costos de transacción parecen indicar que su aceptación institucional irá en aumento. Sin embargo, estas organizaciones necesitan estar muy al tanto de la importancia de la participación adecuada y amplia de las partes interesadas.

Las experiencias con cuencas en los países en desarrollo indican que para que estas organizaciones prosperen tienen que tomar en consideración las capacidades y circunstancias nacionales, obtener recursos suficientes - que incluyen fuentes de ingresos autónomas- y tener mandatos claros y facultades legales suficientes. Los procesos de formación de capacidades y el conocimiento de los factores generales (económicos, sociales, ambientales y culturales) son requisitos previos importantes para la creación y consolidación de las organizaciones de cuencas.

\section{Escasa participación del público}

Algunos países aplican normas bien elaboradas para la participación de los interesados. Sin embargo, en un gran número de países en desarrollo los espacios de participación no están bien organizados, y cuando lo están, tienden a permitir una mayor participación en asuntos ambientales que en cuestiones económicas y sociales. Por ello, los intereses especiales bien organizados tienen más posibilidades de acceso que otros y pocos contrapesos salvo el criterio del regulador o el administrador público, que a su vez pueden verse afectados por el fenómeno de captación. Dos ejemplos latinoamericanos, analizados en el presente artículo, ilustran esta situación. El resultado definitivo es que al reflejar sólo una parte de los intereses en juego, la toma de decisiones sobre el agua no tiene en cuenta todos los factores pertinentes y obstaculiza por lo tanto la gestión integrada y la sustentabilidad. Las decisiones ineficientes a su vez dan origen a la falta de equidad, ya que los escasos recursos financieros e hídricos se asignan sobre la base de la capacidad de negociación.

\section{La información}

Se menciona cada vez más la información como la base para la toma de decisiones atinadas y como medio para el control social de los procesos que se ocupan de las aguas de utilidad pública.

Hay ejemplos legislativos de gestión integrada de la tierra y del agua, de integración del agua superficial y subterránea y de control de la calidad y cantidad. Sin embargo, la mayoría de los casos de integración se observaron en los países desarrollados y no en los países en desarrollo.

\section{Los derechos de agua y la planificación}

Como el agua tiene valor económico, los derechos de aguas y sus mercados adquieren importantes dimensiones. Se han identificado sistemas que abarcan un amplio espectro de alternativas. La evaluación de sistemas de derechos de agua incondicionales, muy individualistas, indica que no promueven la integración de la gestión, ni la eficiencia ni la equidad. En el otro extremo hay sistemas que condicionan los derechos de agua a las necesidades de la planificación. En los sistemas más desarrollados los mercados del agua toman en consideración los asuntos de interés público, que de hecho reflejan los factores relevantes para la gestión integrada del agua. Al menos dos expertos corroboran que la planificación, programación, fijación de puntos de referencia y participación son elementos importantes en la comercialización del agua. 
Estrechamente relacionado con lo anterior está el interrogante de qué hacer cuando los derechos de agua ya existentes son incompatibles con las decisiones de planificación. La pregunta es importante porque si los derechos no condicionados no son óptimos, la incertidumbre legal frente a las condiciones futuras puede impedir la inversión. Las otras respuestas a esta pregunta incluirían: regulación de la función del agua mediante la vigilancia pública y la estipulación de requisitos de eficiencia y el respeto, o indemnización eventual, en caso de anulación de los derechos utilizados efectiva y beneficiosamente.

\section{La fijación del precio del agua}

Varias leyes mencionan y aceptan las medidas financieras y la tarifación del agua como instrumentos claves para la gestión del recurso. No obstante, hay resistencia de los interesados en algunos países que apuntan a la necesidad de indicar bien las condiciones cuando se otorgan derechos de agua.

\section{Los límites de la planificación}

Aunque el objetivo global de la planificación es preservar y ofrecer agua de cierta calidad en un momento determinado, para el desarrollo, la sustentabilidad $\mathrm{u}$ otros fines, hay preguntas importantes: a) ¿hasta dónde es práctico planificar dadas las restricciones e incertidumbres?; b) ¿hasta qué punto los derechos de propiedad adquiridos impiden la integración de la gestión de los recursos hídricos, o al menos cómo deberían considerarse? (Beck y Goplerud (eds.), 1991, pp. 575 y siguientes).
En todo caso, el ámbito de la planificación, que antes se concebía como el desarrollo ordenado y técnicamente correcto de las obras hidráulicas, se ha expandido para incluir $¡$ a sustentabilidad y las cuestiones sociales y económicas.

Es aquí donde la gestión integrada tiene que esforzarse por lograr un equilibrio entre la previsión de la planificación y la necesidad de mantener la capacidad estratégica de ajustarse a condiciones cambiantes, y más aún en una economía mundial. He aquí por qué algunos expertos sostienen que lo que debería planificarse es lo que es necesario y lo que es posible. La pregunta pertinente es qué es lo posible y qué es lo necesario. La respuesta podría estar estrictamente relacionada con las condiciones locales, pero la sustentabilidad general parece ser una condición sine qua non, salvo en circunstancias muy específicas, como el agotamiento planificado de los acuíferos que no se recargan.

Asimismo, si la sustentabilidad se interpreta en términos de la sustentabilidad económica, ambiental y social, orientada por criterios de equidad y eficiencia, la planificación tiene que echar mano de las ciencias de la economía, la sociología y la ecología. Además, en un mundo cambiante, integrado en su totalidad, la planificación con fines económicos debería tal vez hacer suyos algunos conceptos y técnicas de la gestión estratégica del sector privado.

En este contexto, la integración tiene implicaciones geográficas, ambientales y socioeconómicas. Comprende un enfoque basado en la cuenca, la gestión conjunta del agua superficial y subterránea, la integración de la calidad y cantidad del agua y la internalización de las externalidades mediante los principios del que contamina paga y el usuario paga.

(Traducido del inglés)

\section{Bibliografía}

Anderson L.O. y otros (1991): Realloeation, R.E. Beck y P.C. Goplerud (eds.), Waters and water rights, vol. 2, Charlottesville, Virginia, The Michie Company.

Argentina, Ministerio (le Economía y Obras y Servicios Públicos, Subsecretaría de Energía (1997): Evaluación económica del Proyecto Potrerillos, Buenos Aires, 27 de febrero.

Barraqué B. (1992): Water management in Europe: beyond the privatization debate, Flows and Stocks of Fixed Capital, $\mathrm{N}^{\circ} 7$, Part's, OCDE (Organización de Cooperación y Desarrollo Económicos), marzo.

(1997): Integrated water resources management in China: The scope for change, Nanking International Symposium, 22 al 25 de abril.

Beck, R.E. y P.C. Goplerud, eds. (1991): Waters and water rights, Charlottesville, Virginia, The Michie Company.
CEPAL (Comisión Económica para América Latina y el Caribe), División de Recursos Naturales y Energía (1995); Planes y marcos regulatorios para la gestión integrada de cuencas, LC/R.1487, Santiago de Chile.

Colby-Saliba, B. y D. Bush (1987): Water markets in theory and practice: Market transfers, water values and public policy, Studies in water policy and management, $\mathrm{N}^{\circ} 12$, Boulder, Colorado, Westwiew press.

Coñac F. (1989): Land and water rights issues in irrigated schemes in sub-Saharan Africa and Madagascar-conflicts that might be avoided, DWWK Bulletin, $\mathrm{N}^{\circ} 16$, Situation Specific Management, International Irrigation Symposium, Berlin, Verlag Paul Parcy.

Cubillos, G. (1994): Buses para ja formulación de leyes referidas a los recursos hídricos, LC/R. 1387, Santiago de Chile, CEPAL, División de Recursos Naturales y Energía. 
Da Cunha, L.V. (1989): Water resources situation and management in the EEC, Hydwgeology, $\mathrm{N}^{\circ} 2$.

Detlapenna, J. (1991): Regulated Riparianism, R.E, Beck y P.C, Goplerud (eds,), Waters and water rights, vol. 1, Charlottes vil le, Virginia, The Michie Company.

Estados Unidos, Water Resources Council (1971): Proposed principles and standards for planning water management and related natural resources, Office of the Federal Register, vol. $36, \mathrm{~N}^{\circ} 245$, Washington D.C., 21 de diciembre.

Financial Times (1996): Water Report, $\mathrm{N}^{\circ} 6$ Londres, 4 ele septiembre.

Furuseth O. y C. Cocklin (1995): An institutional framework for sustainable resource management: The New Zealand model, Natural Resources Journal, vol. 35, $\mathrm{N}^{\circ}$ 2, New Mexico, University of New Mexico School of Law.

Haddad, B.M. (1996): Evaluating the market niche: Why long-term rural-to-urban inter-regional markets for water have not formed in California, Berkeley, California, University of California, tesis de doctorado.

Hearne, R.R. y otros (s.f.): Water allocations and water markets: an analysis of gains from trade in Chile, Technical Paper $\mathrm{N}^{\circ}$ 315, Banco Mundial, Washington D.C.

Hilt, C. y otros (1996): Administración estratégica: un enfoque integrada, Santafé de Bogotá, Editorial Interamericana.

Howe, C. (1996a): Water resources planning in a federation of states: Equity vs. Efficiency, Natural Resources Journal, vol. 36, New Mexico, University of New Mexico School of Law.
Howe, C. (1996b): Protecting public values under tradable water permit systems: Efficiency and equity considerations, Boulder, Colorado, noviembre.

Kelley-Pittman, A. (1991): Planning and authorization of federal water projects, R.E. Beck y P.C. Goplerud (eds.), Waters and water rights, vol. 1, Charlottesville, Virginia, The Michie Company.

Kemper, K.E, (1996): The cost of free water: Water resources allocation anil use in the Cum Valley, Ceará, Northeast Brazil, Linkoping Studies in Arts and Science, $\mathrm{N}^{\circ}$ 137, Linkoping, Suecia.

Matthews, O.P. (1994): Changing the appropriation doctrine under the model statute water code, Water Resources Bulletin, vol. 30, $\mathrm{N}^{\circ} 2$, Bethesda, Maryland, American Water Resources Association.

Mitchel, B. (Ed.) (1989): Integrated water management: International experiences and perspetives, Londres, Bellhaven Press.

Peña, H. (1996): Modificaciones al código de aguas y su aporte a la gestión del agua, Seminario Internacional Gestión del Recurso Hídrico, Santiago de Chile, Organización de las Naciones Unidas para la Agricultura y la Alimentación (FAO), diciembre.

The New York. Times (1991): Federal judge orders review of rules on irrigation water, Nueva York, 1 de agosto, p. A 14.

Wright, R. y otros (1978): Land use, St. Paul, Minnessotta, West Publishing Co. 